\title{
Position Control Using Fuzzy Logic
}

\author{
Maher M. F. Algreer and Dr. F. H. Ali \\ Email:Maher.algreer@gmail.com \\ Computer Engineering Departement \\ College of Engineering \\ University of Mousl
}

\begin{abstract}
Fuzzy logic controllers have been emerged as one of the most active and useful research areas in the field of fuzzy control theory. That is fuzzy logic controllers haven successfully applied for controlling various physical processes.

This paper shows how fuzzy logic is used for position control application. Three types of Fuzzy Controllers are implemented and their position control response is measured. Two of them are FPI, FPD with two inputs $(\mathrm{e}, \Delta \mathrm{e})$. The third controller is build via connecting the first two in parallel. Two dimensional rule bases, with seven memberships for both inputs and output, are used to perform the control action. Computer simulation is guided to illustrate the performance and show the result for the three types.
\end{abstract}

Keywords: Fuzzy PID Controller, Positional Control, Error, Change of Error.

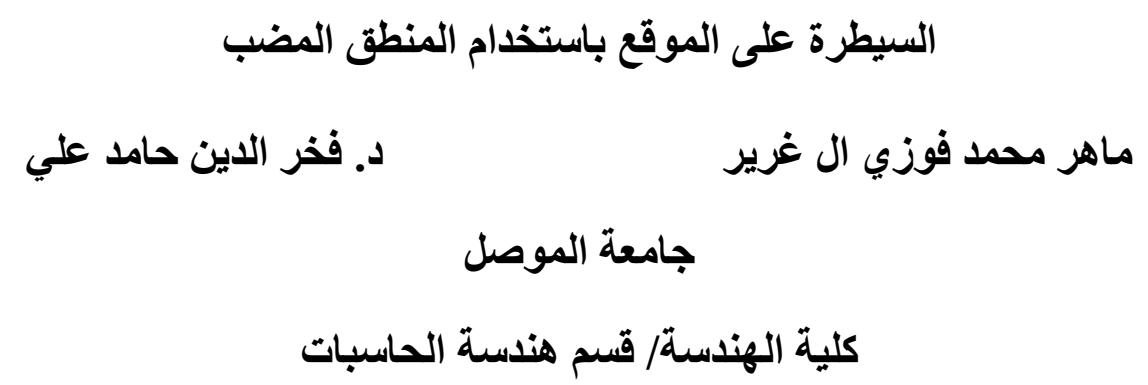




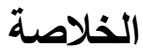

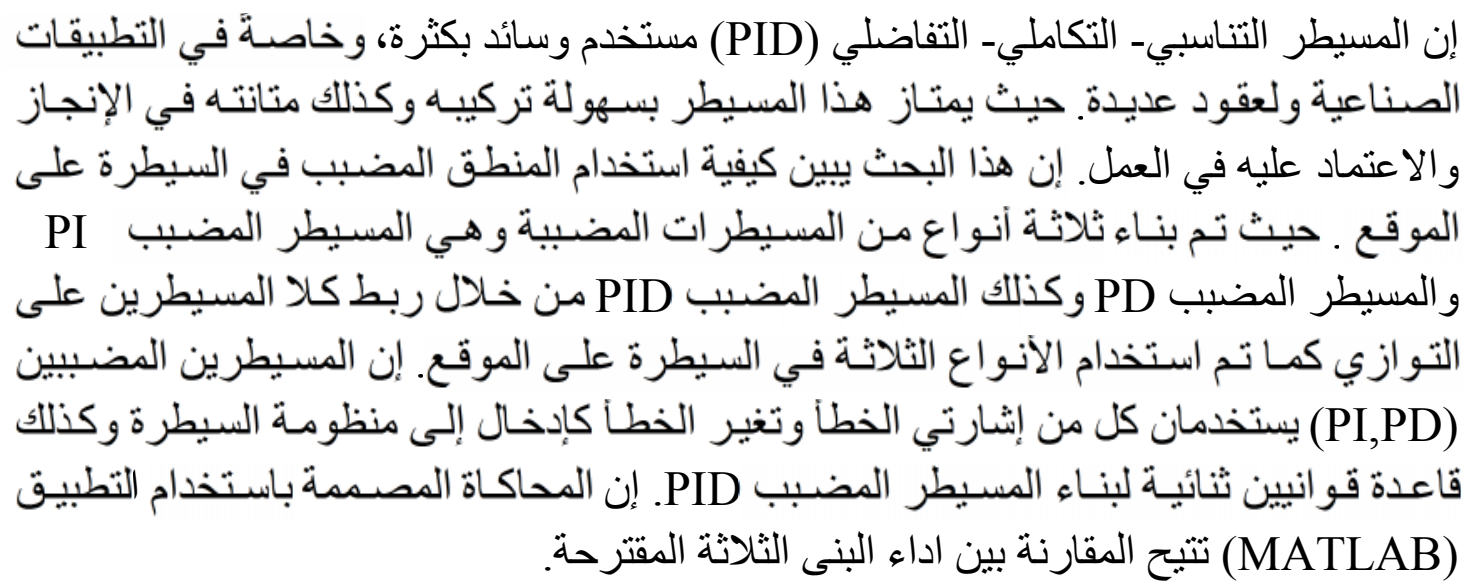

\section{Introduction}

Received 17 Aug. 2005

Accepted 31 May

Over the past two decades, the field of fuzzy controller applications has broadened to include many industrial control applications, and significant research work has supported the development of fuzzy controllers [1]. However, a systematic design of fuzzy controllers is still of great concern due to the following facts. First, there is lack of sufficient theories to show that why fuzzy control, either sometimes or most of time, is able to outperform over the conventional control. Second, there is limited knowledge or design guideline available regarding implementation aspect. For this reason, fuzzy control design usually requires a quite amount of "trial and error" procedure tasks as compared with the straightforward tuning procedures of conventional PID controllers. All these weaknesses have greatly hindered the extensive researches on fuzzy controllers and their application in industry [2]. 
On the other hand, despite a lot of studies and the huge number of different solutions proposed, most industrial control systems are still based on conventional PID regulators. Different sources estimate the share taken by PID controllers at between 90 and $99 \%$. The main reason is due to their simple structure and robust performance in a wide range of operating conditions $[3,4]$.

Just as in conventional control, there are also proportional-derivativetype fuzzy logic control (FZ-PD), proportional-integral-type fuzzy logic control (FZ-PI), and proportional-integral-derivative-type fuzzy logic control (FZ-PID). FZ-PI control is good for steady-state response and FZ-PD control for the transient response, combination of these two means that good performance should be able to be achieved in both the transient and steady state period. FZ-PD/ PI control has achieved research and industrial applications, FZ-PID control (the fuzzy counterpart of the conventional PID control) is still at its early stage of development [5].

\section{Fuzzy logic in control system}

A block diagram of a fuzzy system is shown in the Fig. 1.a. The fuzzy controller is composed of the following three stages [6]:

\subsection{Fuzzification}

Controller inputs, the tracking error signal (position) and the change of the error signal (velocity) are converted into information that the inference mechanism can easily use to activate and apply rules. As shown in Fig. 1.b, there are two inputs to the controller: error and

$$
e(n T)=\theta_{r}(n T)-\theta_{c}(n T)
$$

change of the error signals. The error is defined as:

And the change of error is defined as follows:

$$
\Delta e(n T)=e(n T)-e(n T-T)
$$

Where $\mathrm{T}>0$ is the sampling period, $\theta_{\mathrm{r}}(\mathrm{nT})$ is the reference input, $\theta$ c(nT) is the output signal, e(nT) is the error signal, $\Delta \mathrm{e}(\mathrm{nT})$ is the change of the errofirgirgainl.

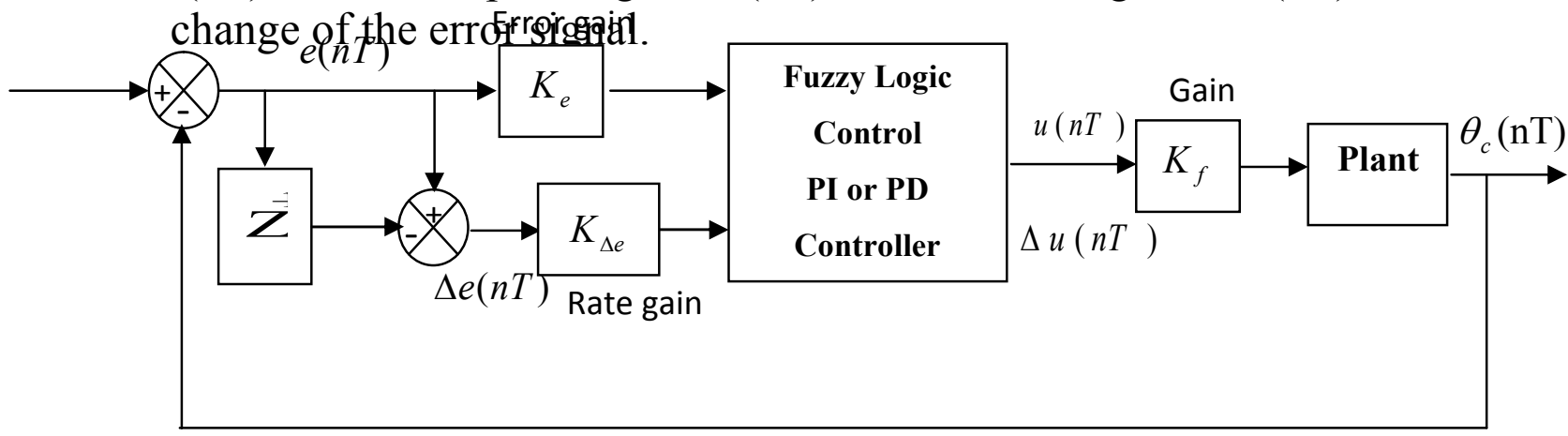




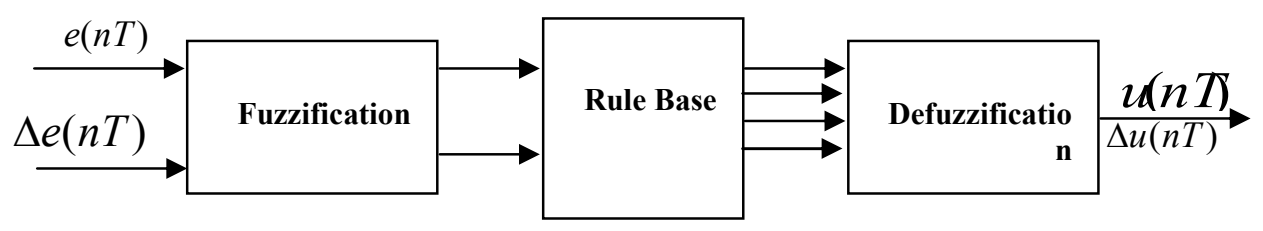

Figure 1.a: Fuzzy logic system.

The fuzzy control shown in Fig. 1.b has a single output, called the incremental control output and is denoted by $\Delta \mathrm{u}_{\mathrm{PI}}(\mathrm{nT})$ if the fuzzy PI controller is assumed, and $u_{\mathrm{PD}}(\mathrm{nT})$ if the fuzzy PD is adopted. So when using PI controller a discrete recursive procedure is used to obtain the signal $\mathrm{u}_{\mathrm{PI}}(\mathrm{nT})$ before application to the plant as represented by the $u_{P I}(n T)=u_{P I}(n T-T)+\Delta u_{P I}(n T)$

following equation:

So the fuzzy controller which is constructed from individual PI and PD controllers, with common inputs, has a combined output to perform as a fuzzy PID controller as shown in Fig. 2.

$u_{P I D}(n T)=u_{P I}(n T)+u_{P D}(\mathrm{nT})$

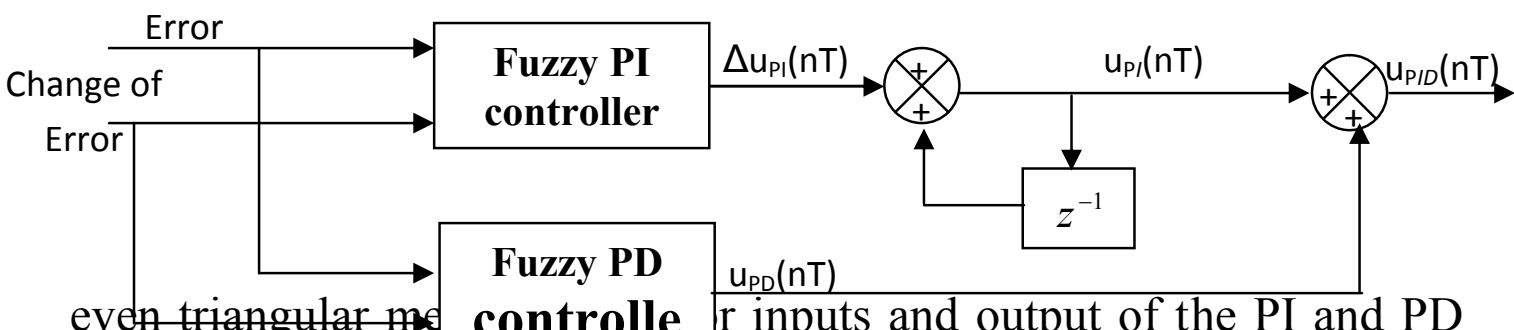

even triangular controlle $\mathrm{r}$ inputs and output of the PI and PD are illustrated in Fig.3. For the system under study the universe of

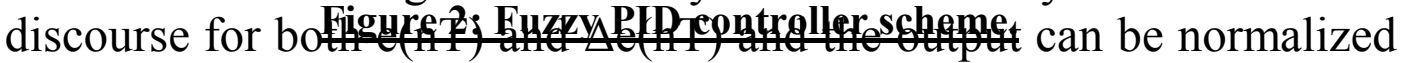
to be in the range $[-1,1]$, and the linguistic labels are Negative Large, Negative Medium, Negative Small, Zero, Positive Small ,Positive Medium, Positive Large\}, and are refereed to in the rule base as $\{$ NL,NM,NS,ZR,PS,PM,PL\}, respectively.

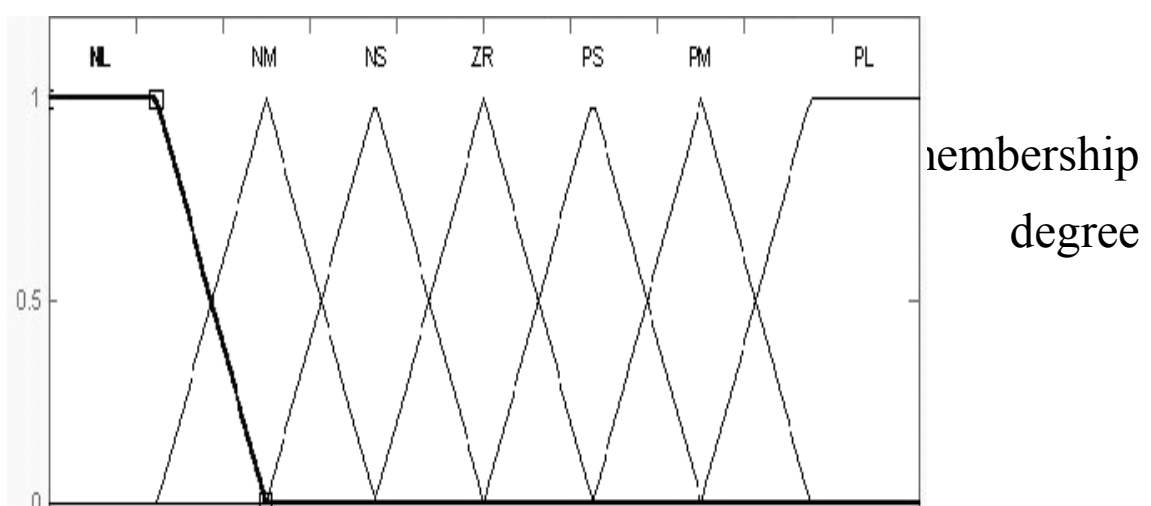




\subsection{Rule base}

A rule base is a set of (IF-Then) rules, which contains a fuzzy logic quantification of the expert linguistic description of how to achieve good control [6].

The basic rule base of these controller types is given by:

Where $E_{i}$ and $E_{j}$ are the linguistic labels input, $U_{m}$ is the linguistic label output.

For the given input and output linguistic label, tables (1) and (2) show the control rule bases that are used for fuzzy PI and fuzzy PD respectively. These tables are adopted from references $[6,7]$.

Table 1: Rule bases for fuzzy PI controller

\begin{tabular}{|l|l|l|l|l|l|l|l|}
\hline & NL & NM & NS & ZR & PS & PM & PL \\
\hline NL & NL & NL & NM & NM & NS & NS & ZR \\
\hline NM & NL & NM & NM & NS & NS & ZR & PS \\
\hline NS & NM & NM & NS & NS & ZR & PS & PS \\
\hline ZR & NM & NS & NS & ZR & PS & PS & PM \\
\hline PS & NS & NS & ZR & PS & PS & PM & PM \\
\hline PM & NS & ZR & PS & PS & PM & PM & PM \\
\hline PL & ZR & PS & PS & PM & PM & PL & PL \\
\hline
\end{tabular}

Table 2: Rule bases for fuzzy PD controller

\begin{tabular}{|l|l|l|l|l|l|l|l|}
\hline $\mathrm{X}$ e & NL & NM & NS & ZR & PS & PM & PL \\
\hline
\end{tabular}




\begin{tabular}{|l|l|l|l|l|l|l|l|}
\hline NL & NL & NS & PS & PB & PB & PB & PB \\
\hline NM & NL & NM & ZR & PM & PM & PB & PB \\
\hline NS & NL & NM & NS & PS & PM & PB & PB \\
\hline ZR & NL & NM & NS & ZR & PS & PM & PB \\
\hline PS & NL & NL & NM & NS & PS & PM & PB \\
\hline PM & NL & NL & NM & NM & ZR & PM & PB \\
\hline PL & NL & NL & NL & NL & NS & PS & PB \\
\hline
\end{tabular}

\subsection{Deffuzification}

The input for defuzzification is the member ship (certainty) $\mu\left(u_{i}\right)$ from implied fuzzy sets resulted from premise rules, and the output is a crisp number. For both fuzzy PI and PD controllers, the most popular method, the center of gravity or area is used for defuzzification which

$$
u_{P D}(n T) \text { or } \Delta \mathrm{u}_{\mathrm{PI}}(n T)=\frac{\sum_{\mathrm{j}=1}^{n} \mu\left(u_{j}\right) \mathrm{u}_{\mathrm{j}}}{\sum_{j=1}^{n} \mu\left(u_{j}\right)}
$$

is presented in the following equation[8]:

Where $\mu\left(u_{j}\right)$ is the member ship grade of the element $u_{j}$, $u_{P D}(n T)$ or $\Delta \mathrm{u}_{\mathrm{PI}}(\mathrm{nT})$ is the fuzzy control output and $\mathrm{n}$ is the number of discrete values on the universe of discourse.

\section{Modeling of the positional control system}

The error detector sends a signal to the dc amplifier which is proportional to the difference between the angular positions of the reference input shaft and the output shaft. As shown in Fig. 4, a dc amplifier amplifies the error signal whose output drives the armature of a permanent-magnet dc motor. If the system works properly, whenever there is a misalignment between the input and the output shafts, the motor will rotate in such a direction as to reduce the error signal to a minimum. The current in the filed of the dc motor is held constant [9].

The estimated values of the system parameters are given in table (3). The open loop transfer function of the system can be obtained as the following equation [9] : 


$$
G(s)=\frac{\theta_{c}(s)}{\theta_{e}(s)}=\frac{K_{s} \mathrm{~A} \mathrm{~K}_{\mathrm{i}} \mathrm{n}}{\mathrm{R}_{\mathrm{a}} \mathrm{B}_{\mathrm{me}} \mathrm{s}\left(1+\tau_{\mathrm{a}} s\right)\left(1+\tau_{m e} s\right)+K_{b} \mathrm{~K}_{\mathrm{i}} \mathrm{s}}
$$

, $\quad \mathrm{J}_{\mathrm{me}}$ and $\mathrm{B}_{\mathrm{me}}$ are the equivalent inertia and viscous $\tau_{a}=\frac{L_{a}}{R_{a}}, \tau_{\mathrm{me}}=\frac{J_{m e}}{B_{m e}}$ Where frictional coefficient seen by the motor, $J_{m e}=J_{m}+n^{2} J_{L}$

respectively, and:

$R_{\text {me }}=\overline{1} . B_{K_{i}}$ todit $^{2} / R_{\mathrm{e}} \mathrm{d} / \mathrm{sec}$

When the values of the system parameters are substituted into eq. (7) the open loop transfer function, neglecting $\tau_{a}$, is reduced to the second

$$
G(s)=\frac{\omega_{n}^{2}}{s\left(s+2 \varsigma \omega_{n}\right)}
$$

order equation:

Where the natural undamped frequency of the system is:

$$
\omega_{n}= \pm \sqrt{\frac{K_{s} \mathrm{~A} \mathrm{~K} \mathrm{i}}{R_{a} \mathrm{~J}_{\mathrm{me}}}}
$$

The damping ratio is:

$$
\varsigma=\frac{K_{b} \mathrm{~K}_{\mathrm{i}}+\mathrm{R}_{\mathrm{a}} \mathrm{B}_{\mathrm{me}}}{2 R_{a} \mathrm{~J}_{\mathrm{me}} \omega_{\mathrm{n}}}
$$

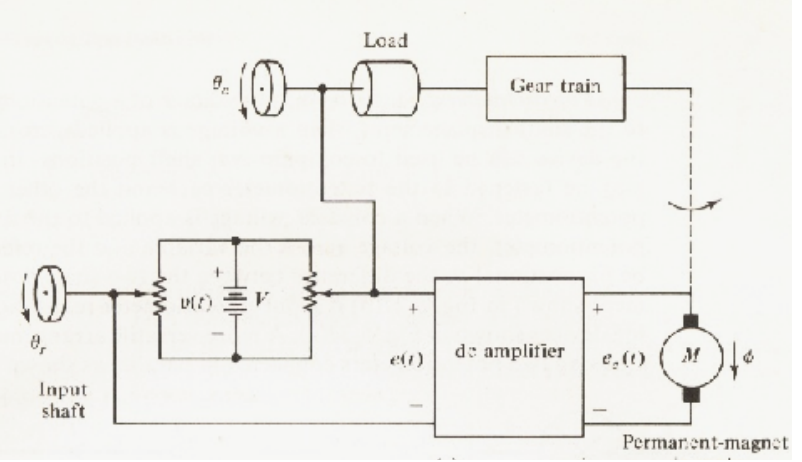

Figure 4: Direct current positional control system. 
Suppose that $\mathrm{La}=0.1$ henry in the positional control system, the open loop transfer function of the third order model is:

$$
G(s)=\frac{250 A}{s\left(s^{2}+50.5 s+1725\right)}
$$

In this paper second order and third order models of the positional control system are used to control the position of a load at different amplifier gain values.

Table3: Positional control system parameters

\begin{tabular}{|l|l|l|}
\hline Parameters & Description & Estimated Value \\
\hline $\mathrm{K}_{\mathrm{s}}$ & Sensitivity of error detector & $1 / 57.3$ volt/deg \\
\hline $\mathrm{A}$ & Gain of dc amplifier & Variable \\
\hline $\mathrm{R}_{\mathrm{a}}$ & $\begin{array}{l}\text { Resistance of armature of } \\
\text { motor }\end{array}$ & $5 \Omega$ \\
\hline $\mathrm{L}_{\mathrm{a}}$ & $\begin{array}{l}\text { Inductance of armature of } \\
\text { motor }\end{array}$ & $0.1 \mathrm{H}$ \\
\hline $\mathrm{J}_{\mathrm{m}}$ & $\begin{array}{l}\text { Inertia of rotor of motor } \\
\mathrm{B}_{\mathrm{m}}\end{array}$ & Friction of motor shaft \\
\hline $\mathrm{B}_{\mathrm{L}}$ & Friction of load shaft & $\mathrm{Negligible}$ \\
\hline $\mathrm{J}_{\mathrm{L}}$ & Inertia of load & $0.1 \mathrm{Ib}-\mathrm{ft}-\mathrm{sec}^{\wedge} 2$ \\
\hline $\mathrm{N}$ & Gear ratio & $\mathrm{N} 1 / \mathrm{N} 2=1 / 10$ \\
\hline
\end{tabular}




\begin{tabular}{|c|c|c|}
\hline $\mathrm{K}_{\mathrm{i}}$ & Torque constant of motor & $\begin{array}{ll}0.5 \quad 0.1 & \text { Ib- } \\
\text { ft/amp }\end{array}$ \\
\hline
\end{tabular}

\section{Simulation results}

The computer simulation is supervised by MATLAB SIMULINK and FUZZY TOOLBOX. Third and second order representation of the positional control system models are used, and then these models are converted into discrete time input-output. Tuning the gain of the fuzzy controllers is achieved in many steps. In each step the scaling gains, for both input and output, are varied and the response is measured. The values which produced the best response are fixed for each controller, then these controllers are studied further using their fixed gain values. The concluded gain values for each controller are shown in table (4).

Table 4: Scaling gain values

\begin{tabular}{|r|r|r|l|}
\hline Gain / Controller Type & $\mathrm{K}_{\mathrm{e}}$ & $\mathrm{K}_{\Delta \mathrm{E}}$ & $\mathrm{K}_{\mathrm{f}}$ \\
\hline FPI & 0.0625 & 0.75 & 1.5 \\
\hline FPD & 0.25 & 0.01 & 0.5 \\
\hline FPID at FPI & 0.0625 & 0.75 & 0.1 \\
\hline FPID at FPD & 0.125 & 0.1 & 0.1 \\
\hline
\end{tabular}

In

this

simulation Fuzzy PI, Fuzzy PD and Fuzzy PID controllers were implemented, and their responses, for comparison, are shown in Fig. 5, using the second order model, and in Fig. 6, using the third order one. The plant output in the figures represents the angular dispoplacement $\left(\theta_{c}\right)$ in degree.

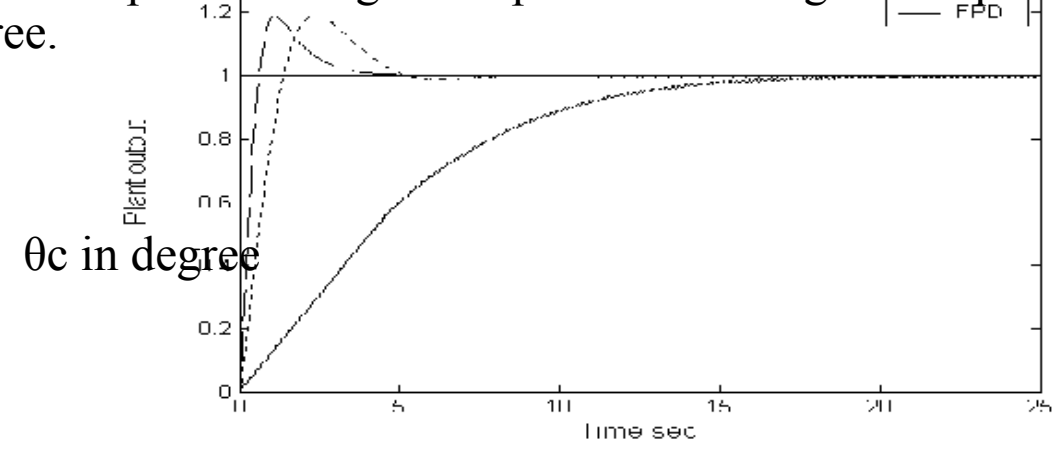

Figure 5: Performance of (FPI, FPID, and FPD) for second order model at A=13.5. 


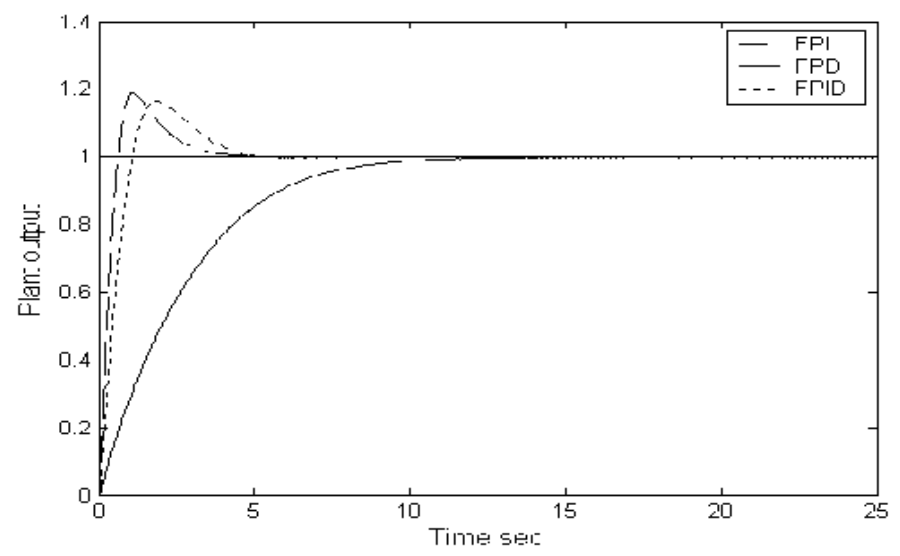

Figure 6: Performance of (FPI, FPD, and FPID) for third order model at A=200.

Fig. (7, 8, and 9) show the transient response of the second order model when the dc amplifier gain is varied.

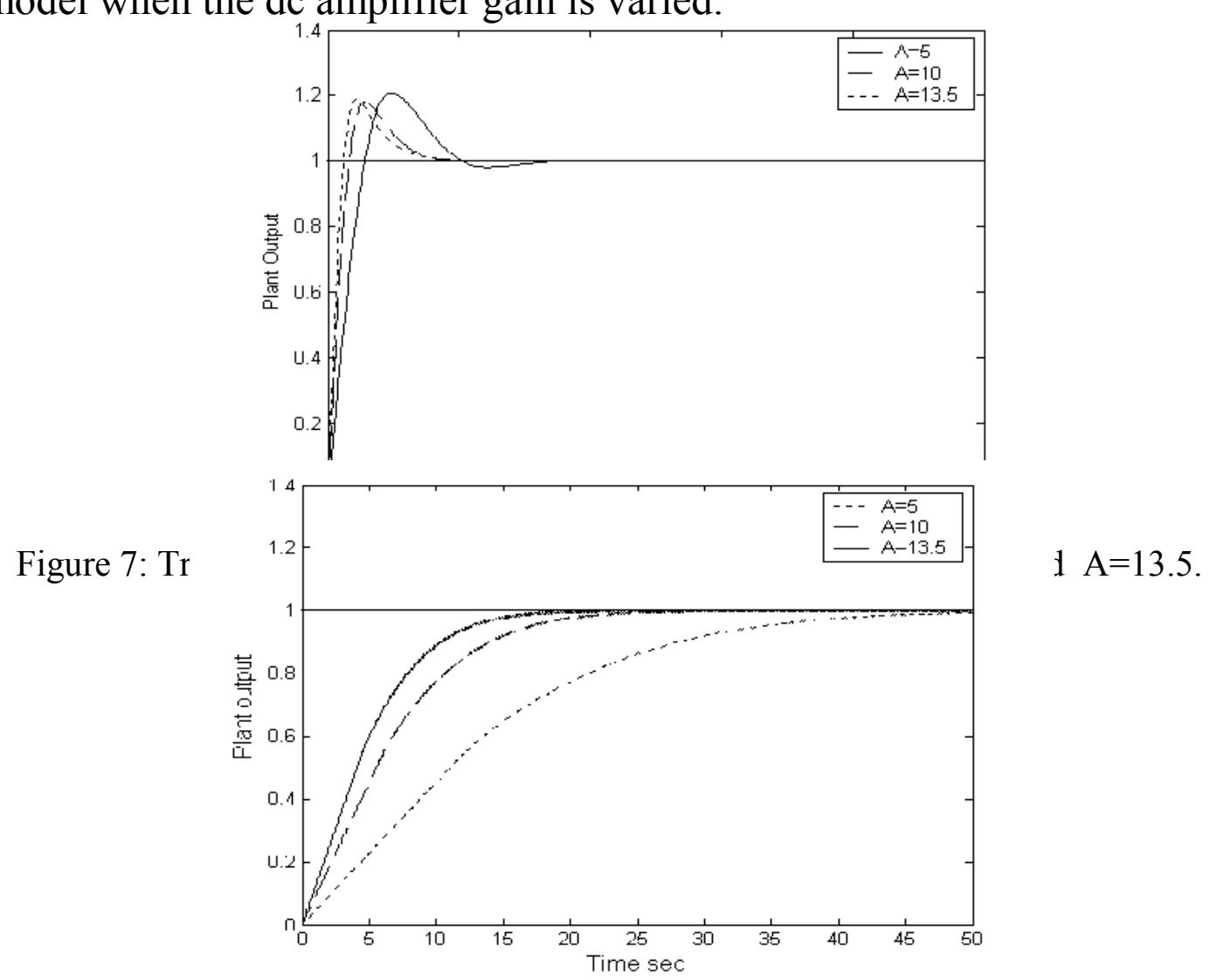

Figure 8: Transient response of the FPD controller at $A=5, A=10$, and $A=13.5$. :

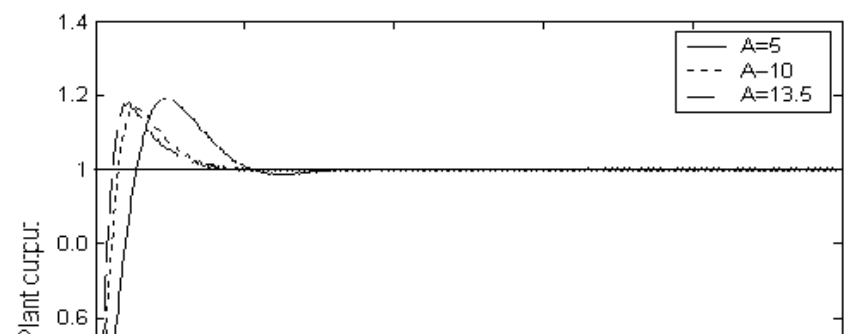


To simulate the positional tracking effect at different cases, the dc amplifier gain value is varied and the response is measured when a ramp input is applied as shown in Fig.10. Additional load tests for each controller are shown in Fig. (11.a,11.b,12.a,12.b,13.a, and 13.b). Zooming is used to notice the fine differenees between the response curves.

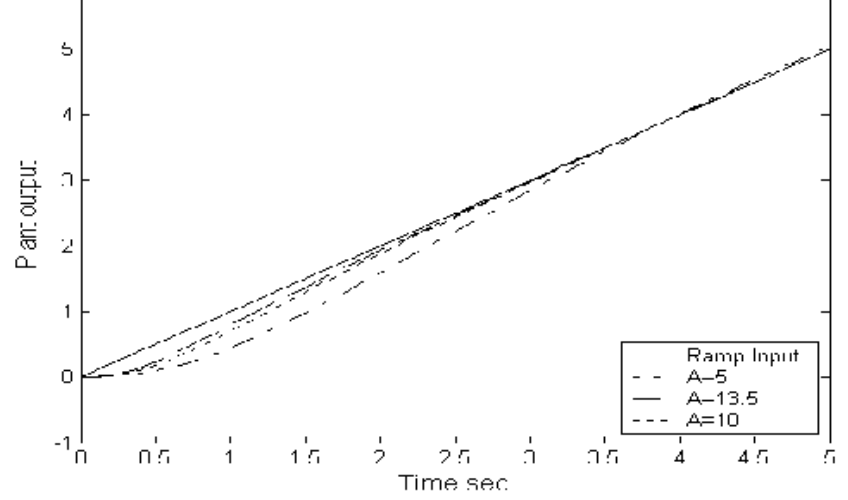

Figure 10: System response and control action with fuzzy PI controller at ramp input.

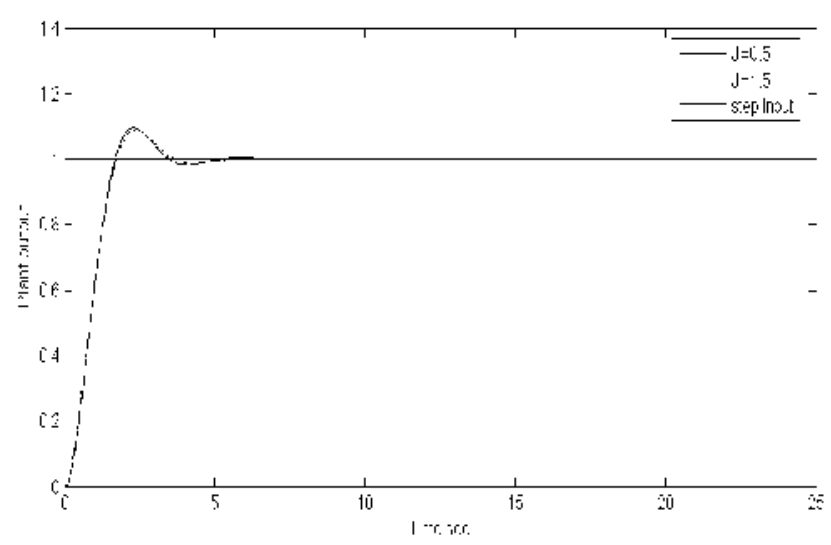

Figure 11.a: Transient response of the system output and control action with fuzzy PI controller at $\mathrm{J}_{\mathrm{L}}=0.5, \mathrm{~J}_{\mathrm{L}}=1.5$. 


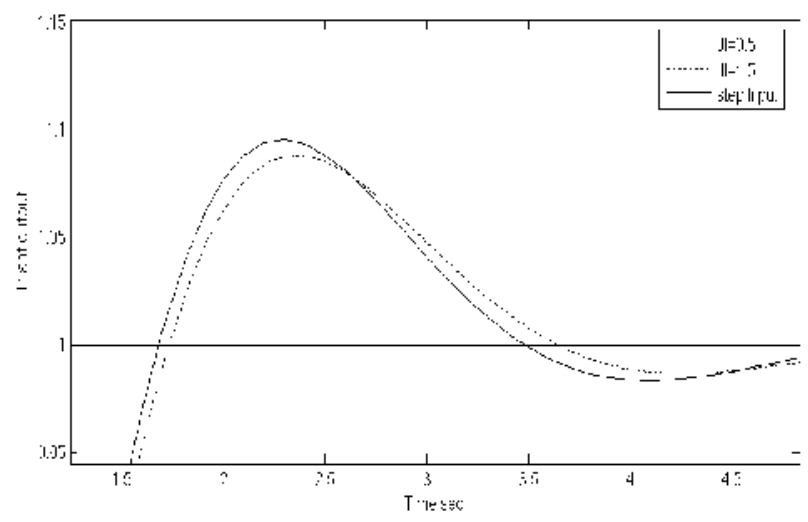

Figure 11.b: Transient response of the system output and control action with fuzzy PI controller at $\mathrm{J}_{\mathrm{L}}=0.5, \mathrm{~J}_{\mathrm{L}}=1.5$ after zooming the figure.

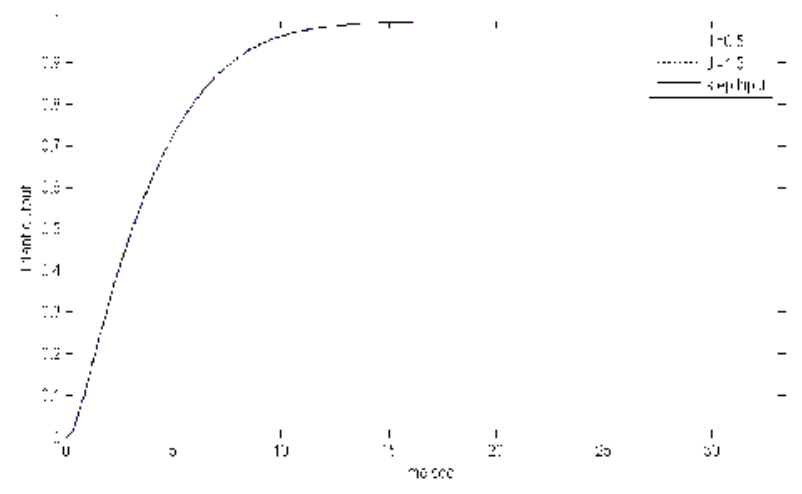

Figure 12.a: Transient response of the system output and control action W

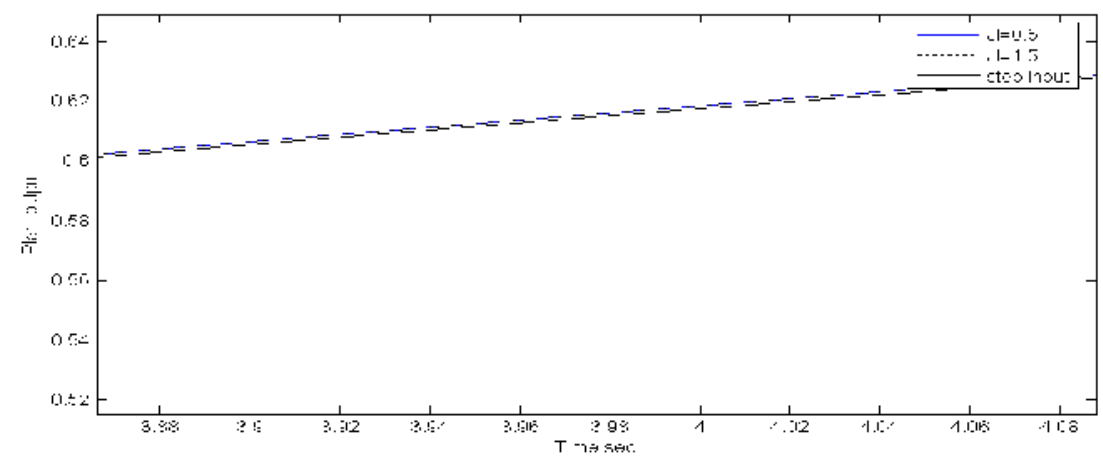

Figure 1 1 .b: Transient response of the system output and control action with fuzzy PD controller at $\mathrm{J}_{\mathrm{L}}=0.5, \mathrm{~J}_{\mathrm{L}}=1.5$ after zooming the figure.

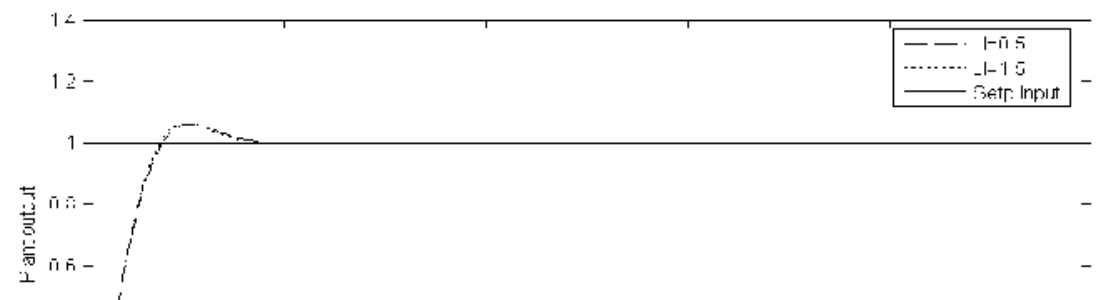


Figure 13.a: Transient response of the system output and control action with fuzzy PID controller at $\mathrm{J}_{\mathrm{L}}=0.5, \mathrm{~J}_{\mathrm{L}}=1.5$.

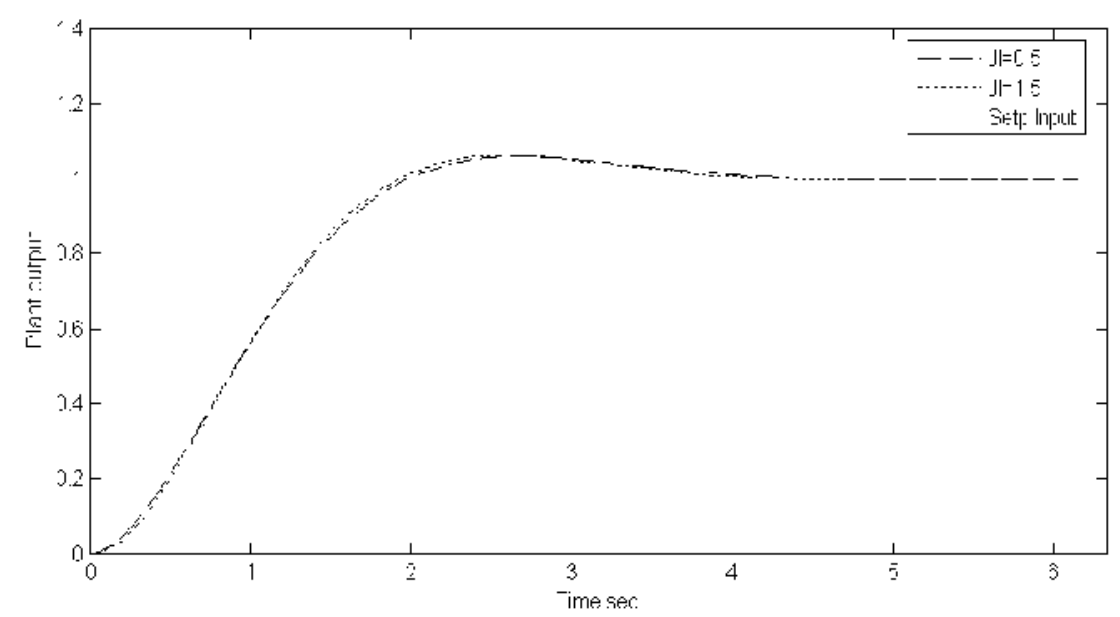

Fig. 13-b Transient response of the system and control action with fuzzy PID controller $\mathrm{JL}=0.5, \mathrm{JL}=1.5$ after zooming the figure. The computation of the fuzzy control action signal composed many steps. These steps can be all combined together, for different inputs, to produce the rule surface viewer or control surface because the system has two inputs and one output. The shape of this surface shows how the output value varies with different combination of the two input values. Fig. (14, and 15) show the control surface of the fuzzy PI and PD respe the error

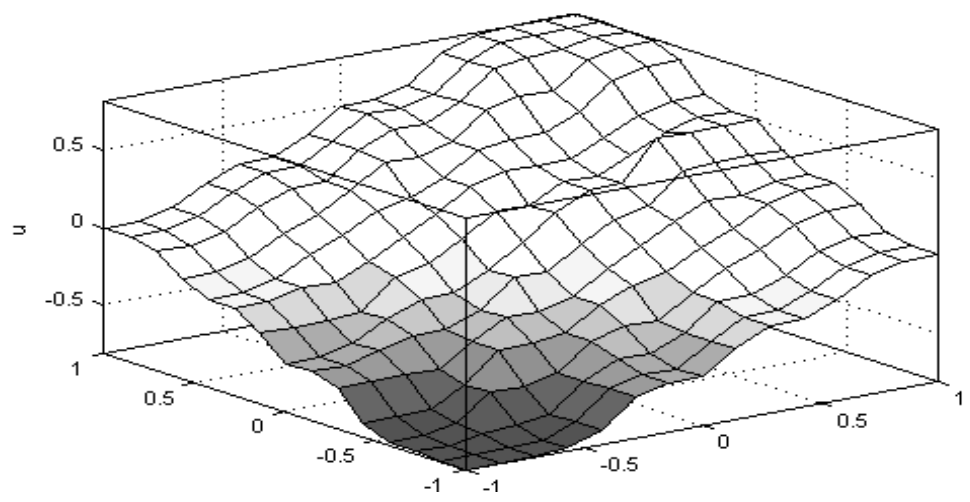
Id (e) is

Figure 14: Control surface of the FPD controller. 


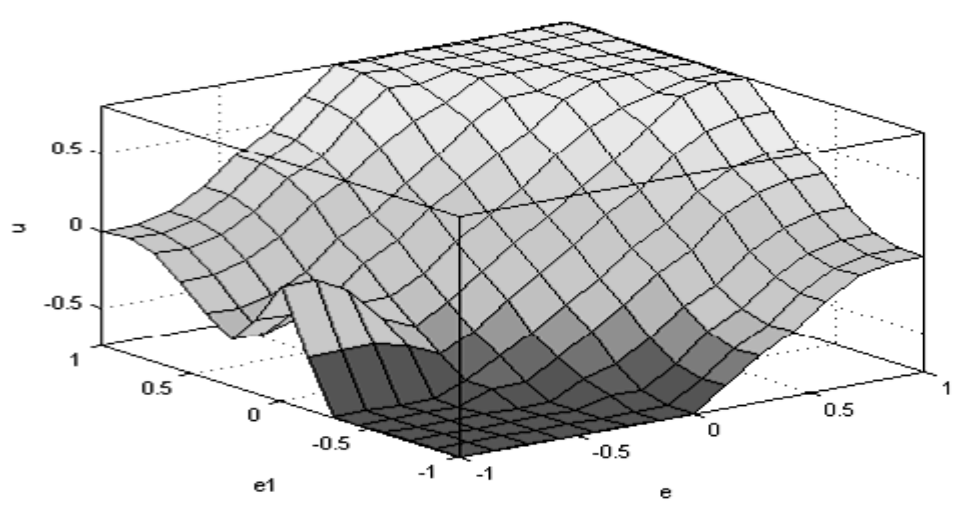

Figure 15: Control surface of the FPI controller

\section{Conclusions}

A two-input fuzzy (PI, PD, PID) controllers are used for implementing a second and a third order models of a position control system. The response due to slight value-change in elements of position control system is studied reaching to the construction which is less affected by this change and conclude the best fuzzy control, out of the three controllers, when some parameters are not known or not constant.

Comparing the response in Fig.5 with that in Fig.6, it can be concluded that equivalent response using $3 \mathrm{rd}$ order $\mathrm{G}(\mathrm{s})$ can be obtained using 2nd order G(s) at different value of the D.C. amplifier gain (A) . This justifies neglecting the time constant $\tau$ a to reduce the 3 rd order system to the simpler 2 nd order one presented in equation (11). For this reason other tests and examinations are carried out using 2 nd order system only.

A slight change of elements value is considered via changing the value of (A). This means indirect changing of each parameter value in equation (12) or (13).

Examination of the response of the three controllers shows that FPID follows a response between FPD and FPI controller responses, as expected, since it is constructed from connecting them in parallel. The response of the FPD controller has no overshoot but it suffers from a longer settling time. When the gain A is increased, the three controllers prove to be stable with no a considerable effect on their response is 
noticed. When the gain A decreases beyond the value 10, a little damped oscillation is just starts to form in the response of the FPI controller. Both the rising time and the settling time are slightly decreased when the gain $\mathrm{A}$ is increased in the three controller types. On the other hand, a change of $\mathrm{J}_{\mathrm{L}}$ values (change of load) from 0.5 to 1.5 , or an increase by $200 \%$, produces a negligible effect on response of the three controllers. This represents testing the effect of load change as illustrated in Fig. $(11,12, \& 13)$.

Since in positional control, the steady state error is more important than other parameters and all the three types of fuzzy controllers in this paper are able to achieve zero steady state error, so all are considered to be successful. However, since FPI takes the least time to settle, it is concluded to be the best construction. Therefore, the FPI controller is tested further to simulate the positional tracking effect by applying another type of input which is the ramp. Its response is examined at three different gain values ( refer to Fig.10) and proven to follow an acceptable performance.

Fig.14 and Fig.15 demonstrate how the crisp output varies with different combinations of the error and change of the error values. This is so important when real time performance is considered which requires implementing the whole system in the hardware after deciding the acceptable resolution immerging from these figures.

\section{References:}

[1]: George K.I.Mann, Bao-Gang $\mathrm{Hu}$, and Raymond G.Gosine, "Analysis of Action Fuzzy PID Controller Structures", IEEE Trans.Syste.,Man, Cybern., vol.29,No.3,pp.371-388, 1999.

[2]: George K.I.Mann, Bao-Gang Hu, and Raymond G.Gosine, "A Systematic study of Fuzzy PID Controllers- Function-Based Evaluation Approach", IEEE Trans.,Fuzzy Syst., Cybern., vol.9,No.5,pp.699-712, 2001.

[3]: Lenid Reznik, Omar Ghanayem, and Anna Bourmistrov, "PID Plus Fuzzy Controller Structures as A Design Base for Industrial Applications", Engineering appliaction of artificial Intelligence, vol.13, No.4, pp.419-430, 2000.

[4]: Hao Ying "TITO Mamdani Fuzzy PI/PD Controllers as Nonlinear, Variable gain PI/PD", International Journal of Fuzzy System, Vol.2, No.3, September, 2000.

[5]: H.-X.LI, and S.K.Tso, "Quantitative Design and Analysis of Fuzzy Proportional-Integral-Derivative Control-a Step Twoards Autotuning", International Journal of System Science, vol.31, No.5, pp.545-553, 2000 . 
[6]: Kevin M. Passino, and Stephen Yurkovich, "Fuzzy Control", Addison Wesley longnan, Inc. 1998.

[7]: Michall Petrov, Ivan Ganchev and Ivan Dragotinv, " Design Aspects of Fuzzy PID Control", International Conference on Soft Computing, Mendel "99", Brno, Czech republic, 9-12, pp.277282,jun. 1999.

[8]: Nikhil D. Kelkar, "A Fuzzy Controller for Three Dimensional Line Following of an Unmanned Autonomous Mobile Robot", University of Cincinnati, MSC thesis, 1997.

[9]: B. C. Kuo,” Automatic Control System”, Prentice-Hall.Inc., 